\title{
Systematic review of studies about countertransference in adult psychotherapy
}

\author{
Revisão sistemática de estudos sobre contratransferência \\ em psicoterapia de adultos
} Diogo de Bitencourt Machado, ${ }^{1}$ Fábio Monteiro da Cunha Coelho, ${ }^{2}$ Augusto Dutra Giacomelli, ${ }^{3}$ Mariana Almeida Lopes
Donassolo, ${ }^{4}$ Morgana Sonza Abitante, ${ }^{5}$ Tatiane Dall'Agnol, ${ }^{6}$ Cláudio Laks Eizirik $^{7}$

\begin{abstract}
Introduction: Countertransference, the emotional reaction of a psychotherapist toward a patient, is an important technical element of psychotherapy. The purpose of this systematic review was to identify and describe the main findings of studies that evaluated countertransference in adult psychotherapy.

Methods: A search was conducted of the databases Embase, PubMed, PsycINFO and Web of Knowledge to retrieve data published in any language at any time.

Results: Of the 1,081 studies found in the databases, 25 were selected. Most were about psychodynamic psychotherapy, and results indicated that positive countertransference, that is, feelings of closeness to the patient, are associated with positive outcomes, such as symptom improvement and good therapeutic alliance.

Conclusions: Although few studies were found in the literature, countertransference seems to be an important source of knowledge about several aspects, such as treatment outcomes, attachment style, therapeutic alliance, patient symptoms and diagnoses.
\end{abstract}

Keywords: Psychotherapy, countertransference, review.

\section{Resumo}

Introdução: Contratransferência, definida como a reação emocional do psicoterapeuta em relação ao paciente, é um elemento técnico importante da psicoterapia. Esta revisão sistemática procura identificar e descrever os principais achados de estudos que avaliaram a contratransferência na psicoterapia de adultos. Métodos: Realizou-se uma busca sem restrição de língua ou data de publicação nas bases de dados Embase, PubMed, PsycINFO e Web of Knowledge.

Resultados: Dos 1.081 estudos encontrados nas bases de dados, 25 foram selecionados. A maioria trata de psicoterapia psicodinâmica e os resultados indicam que a contratransferência positiva, isto é, os sentimentos de proximidade com o paciente, está associada a resultados positivos, tais como a melhora dos sintomas e o desenvolvimento de uma boa aliança terapêutica. Conclusões: Apesar de poucos estudos terem sido encontrados na literatura, a contratransferência parece ser uma fonte importante para o conhecimento do resultado do tratamento, estilo de apego, aliança terapêutica, sintomas e diagnóstico, dentre outros aspectos.

Descritores: Psicoterapia, contratransferência, revisão.

\footnotetext{
${ }^{1}$ Psychiatrist. MSc in Medical Sciences: Psychiatry, Universidade Federal do Rio Grande do Sul (UFRGS), Porto Alegre, RS, Brazil. Universidade Católica de Pelotas (UCPel), Pelotas, RS, Brazil. ${ }^{2}$ Psychiatrist. PhD in Graduate Program in Health and Behavior, UCPel, Pelotas, RS, Brazil. Department of Mental Health, Universidade Federal de Pelotas (UFPel), Pelotas, RS, Brazil. ${ }^{3}$ Psychiatrist, Centro de Atenção Psicossocial (CAPS), São Luiz Gonzaga, RS, Brazil. ${ }^{4}$ Psychiatrist. Residence Program in Psychiatry, Escola de Saúde Pública, São Lourenço do Sul, RS, Brazil. ${ }^{5}$ Psychiatrist. Child and Adolescent Psychiatry, UFRGS, Porto Alegre, RS, Brazil. 6 Psychiatrist, CAPS II, Blumenau, SC, Brazil. 7 Psychiatrist and psychoanalyst. PhD in Medical Sciences: Psychiatry, UFRGS, Porto Alegre, RS, Brazil. Department of Psychiatry and Legal Medicine, UFRGS, Porto Alegre, RS, Brazil.

Financial support: Coordenação de Aperfeiçoamento de Pessoal de Nível Superior (CAPES).

Submitted Jan 14 2014, accepted for publication May 15 2014. No conflicts of interest declared concerning the publication of this article.

This paper is part of dissertation entitled "Contratransferência e aliança terapêutica no início de psicoterapia psicodinâmica de adultos" ("Countertransference and therapeutic aliance in early adult psychodynamic psychotherapy"), presented in 2014 as part of Graduate Program in Medical Sciences: Psychiatry, Universidade Federal do Rio Grande do Sul (UFRGS), Porto Alegre, RS, Brazil.

Suggested citation: Machado DB, Coelho FM, Giacomelli AD, Donassolo MA, Abitante MS, Dall'Agnol T, et al. Systematic review of studies about countertransference in adult psychotherapy. Trends Psychiatry Psychother. 2014;36(4):173-185. http://dx.doi.org/10.1590/2237-6089-2014-1004
} 


\section{Introduction}

Countertransference (CT), defined as the set of emotional responses elicited in the therapist by specific qualities of his/her patient, ${ }^{1}$ has been extensively associated with other constructs found in the psychoanalytic literature, such as projective identification, role-responsiveness and enactment, and in the literature about constructivist/relational theory. ${ }^{2} \mathrm{~A}$ construct widely linked to psychodynamic psychotherapy (PP), but also used in cognitive-behavioral therapy (CBT), CT is a valuable source of information about the patient's internal world. ${ }^{3}$ Other theoretical models, such as systemic and feminist therapy, ${ }^{4}$ have also used CT.

CT was first discussed by Freud in 1910, who described it as the result of the patient's influence on the therapist's unconscious conflicts. ${ }^{5}$ In 1912, he warned against the dangers of CT, as the therapist might get carried away by tender feelings for a patient, and advised that CT should be kept under control. ${ }^{6}$ This construct originated from transference, which, in turn, had been extensively studied since the beginning of psychoanalysis. In a search of a digital edition of the complete works of Freud, the term countertransference was found in only two texts, 5,6 whereas transference was used in several papers, which confirms the difference in the attention given to these concepts. According to Tyson, Freud refrained from further exploring CT because of the sex scandals that involved psychoanalysts and that might expose psychoanalysis to criticism. In letters, Freud suggested that this issue should be addressed among psychoanalysts through discussions and private correspondence. ${ }^{7}$ After these initial discussions, CT seldom appeared in the literature for forty years. Historically, during that time, there was a predominance of a so-called "classical" theoretical model of CT, seen as an obstacle that might contaminate treatments. ${ }^{8}$

The discussion was resumed in 1949 with a model called totalistic, in which CT was defined as a source of communication created by the minds of the patient and the therapist. ${ }^{8}$ In that year, Winicott ${ }^{9}$ presented a paper that discussed the feelings of anger aroused in the analyst during the treatment of psychotic patients. In the following year, Heimann ${ }^{10}$ described CT as an important therapeutic tool. A third author, also involved in the same discussions, was Racker, ${ }^{11,12}$ who has made a vast original contribution since 1953. He described the countertransference neurosis and classified it as concordant or complementary. Concordant CT is the result of ego identification between patient and therapist, which produces a sense of harmony, and complementary CT develops when the therapist identifies with some internal object in the patient, which usually results in unpleasant feelings.

After the totalistic model, CT became an important concept in psychotherapy. Other models have been described: moderate, ${ }^{13}$ in which therapist reaction results from both his/her own reality and the influences received from the patient; relational, ${ }^{14}$ which takes into consideration the mutual creation by patient and therapist; and specific, in which therapist reaction results from a specific patient feature. ${ }^{8}$

The visions of CT over the past 50 years have developed upon the perception that the psychoanalyst is a person that has feelings and a personal and professional identity, and who is a valuable technical element in clinical psychotherapy. ${ }^{15}$ The importance of CT in practice has been described in psychoanalytic theory and the analytic field: CT has a decisive influence on the selection of patients, as the choices made tend to gratify the neurotic needs of the therapist; when properly perceived, CT may be an important resource to understand a primitive means of nonverbal communication, may help visualize blind spots and may be a stimulus for self-analysis.; Moreover, patients often bind specifically to the emotional tone of the therapist. ${ }^{16}$ In CBT, the study of therapist emotions has the potential to help solve a series of current aspects of psychotherapy, such as identifying the effectiveness of therapists, use of manualized therapies, ability to learn and respond to training, reduction of burnout and other issues that affect clinical practice. ${ }^{17}$

Two narrative reviews and a meta-analysis of studies about CT assessment were found in the literature. The first review was conducted in 1977 and included empirical and theoretical studies. It summarized main findings and concluded that theoretical studies are useful to describe CT, whereas empirical studies contribute to the analysis of how CT functions. ${ }^{18}$ The second review, conducted in 2002, focused on studies published after the first review and discussed findings of analogous studies conducted in CT laboratories and in field work within the psychotherapeutic setting. Examples of analogous studies are those that involve the assessment of therapist reactions to a single interview of students that were not undergoing treatment or the assessment of reactions to videos with accounts by patients. These studies are important because $\mathrm{CT}$ is an abstract phenomenon, difficult to be operationalized and measured. Field research, in contrast, is more difficult to control, but has greater applicability. The studies reviewed showed that CT affects therapist cognition, affection and behavior. ${ }^{13}$

A meta-analysis published in 2011 assessed the relation between CT and psychotherapy outcomes and found that CT was inversely related to the outcomes under assessment. ${ }^{14}$ The outcomes were separated into proximal and distal, but were not described in detail, which reduced the significance of the findings reported. The search strategy shifted toward the concept of countertransference management (CTM) and similar studies and field studies 
were pooled. Most studies adopted a specific model of care, called psychological counseling, which is used in outpatient clinics for students and focuses on day-to-day problems, relationships, and social and academic issues.

As a contribution to a critical view of CT, this systematic review briefly describes studies that evaluated $\mathrm{CT}$ in adult psychotherapy and reports on the general characteristics and results found in the literature. The following questions were prepared to guide data analyses: Where and when was the study conducted? What was the theoretical framework of the concept of CT in these studies? What instruments were used and how did they measure CT? What were the settings, patients, therapists and type of therapy? What were the main objectives and results?

\section{Methods}

The search was conducted in Embase, PubMed, Web of Knowledge and PsycINFO in January 2013, with no language or publication date restrictions. The search terms were "countertransference" and "psychotherapy", after their spellings were confirmed in each database. Table 1 shows the strategy used in each database. The studies were collected using the Endnote ${ }^{\mathrm{TM}}$ reference manager. Two reviewers selected the studies individually; they assessed titles and abstracts to check whether the studies met inclusion and exclusion criteria and, if necessary, read the full text for confirmation. The spreadsheets of the two authors were compared, and the differences discussed until a consensus was reached. In case no consensus was reached, a third author made the decision.

Four inclusion criteria were defined: 1) studies evaluated CT using some method or instrument; 2) patients should be older than 18 years; 3) studies should have been conducted in the psychotherapy setting; 4) full-length studies published in peer-reviewed journals. The exclusion criteria were: 1 ) theoretical studies; 2) case reports; 3) CT in laboratory setting; 4) scale validation; and 5) studies about the therapist's mental functioning in general rather than emotional reactions toward a patient.

The list of studies selected for reading was complemented by studies listed in other review studies and the reference lists of selected studies. The authors read the studies critically according to a reading sheet developed for the evaluation of psychotherapy studies, and discussed the studies after that.

\section{Results}

The flowchart in Figure 1 shows the steps followed to select studies, from database search to the final selection of 25 studies. Table 2 shows how studies were evaluated according to the issues defined for this systematic review, as well as other issues that might be useful to readers.

\section{Where and when were the studies conducted?}

Most studies were conducted in the United States (10), followed by Norway (5), Brazil (4), Germany and Sweden (2 each) and Canada and the Netherlands (1 each). The first study was published in $1958,{ }^{21}$ and the second, in $1960 .{ }^{19}$ No studies were published in the $1970 \mathrm{~s}$ and 1980s, and 16 have been published since 2000 .

\section{What is the theoretical framework of the concept of CT in these studies?}

Most studies are linked to psychoanalysis and include a brief review of the concept. CT is defined as a tool to expand the knowledge about the internal world of the patient through the feelings and fantasies elicited in the therapist. These feelings aid in diagnosis and management, $24,26,28,29,32,38,39$ even in the case of pharmacological treatments. ${ }^{23}$

$\mathrm{CT}$, often defined as the therapist's transference, ${ }^{21}$ is part of the field that is created by the interaction of the dyad. ${ }^{25,40} \mathrm{CT}$ is associated with the patient's commitment to the treatment, ${ }^{42}$ should be examined during supervision, ${ }^{23}$ is affected by the therapist's personal characteristics ${ }^{36}$ and is more difficult for beginning therapists. ${ }^{43}$ When not properly identified, it may become an obstacle to treatment, as the therapist may adopt an attitude of avoidance, especially when confronted with unpleasant feelings. ${ }^{19}$

Table 1 - Search strategy used in each database

\begin{tabular}{ll}
\hline Data base & Options selected \\
\hline Embase & $\begin{array}{l}\text { Explosion of terms; MEDLINE; humans; article; neurology and psychiatry; age 18 or older; human, } \\
\text { clinical study, controlled study, normal human, major clinical study, questionnaire, outcomes research, } \\
\text { human experience, qualitative research, clinical trial, control group, correlational study. }\end{array}$ \\
PubMed & $\begin{array}{l}\text { Humans; } 18 \text { years old or more; clinical trial, comparative study, controlled clinical trial, meta-analysis, } \\
\text { randomized controlled study and systematic reviews. }\end{array}$ \\
Web of knowledge & Psychology, psychiatry, neuroscience neurology; articles. \\
PsycINFO & Human; journal; age 18 or older. \\
\hline
\end{tabular}




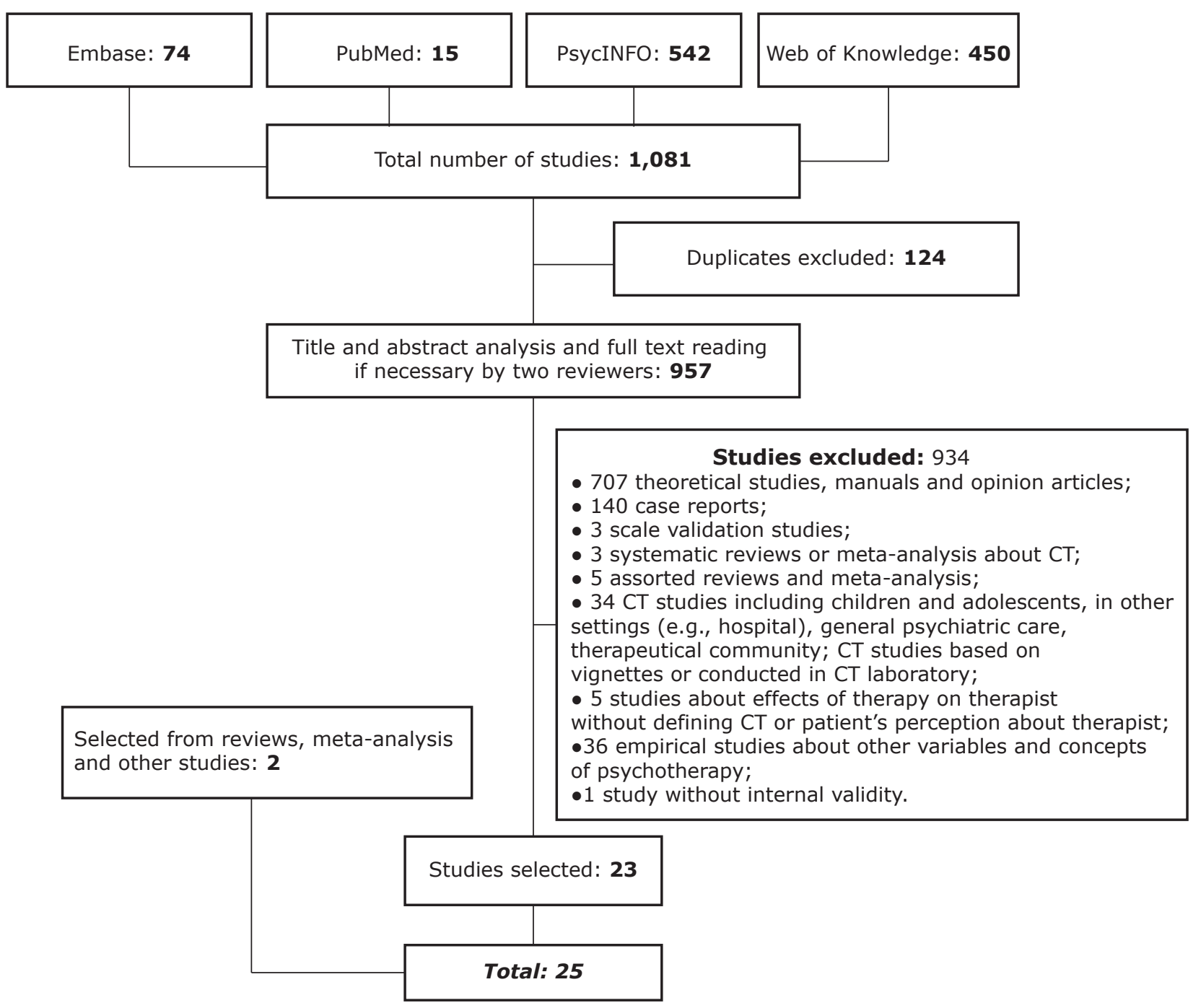

Figure 1 - Study selection. CT = countertransference.

Some studies focused on theories other than psychoanalysis, such as interpersonal theory ${ }^{28}$ and attachment theory. ${ }^{35}$ One study used the Core Conflictual Relationship Theme system to identify the patterns of interpersonal patient feelings, related to the concept of transference. ${ }^{33}$ In a study that focused on interpersonal therapy, CT was called impact message, ${ }^{28}$ and in two studies in which CBT theory was predominant, it was called emotional reactions of the therapist. ${ }^{36,42}$ In addition, two other concepts were identified. In the first, CTB, both positive reactions, such as agreeableness, and negative reactions, such as punitive attitudes, are seen as harmful to the proper development of therapy. ${ }^{34,35}$ The other concept is CTM, ${ }^{27,30,43}$ a technical and theoretical construct useful in psychotherapy supervision and formation. Based on the hypothesis that the level of resolution of therapist intra- psychic conflicts is positively related to their capacity to use CT therapeutically, CTM has five dimensions: origins, triggers, manifestations, management and effects.

\section{What instruments are used and how do they measure CT?}

The studies used 12 different tools. Some included qualitative methods to assess CT. ${ }^{23,24,31,33,41,43} \mathrm{All}$ instruments assessed some aspect of CT elicited after one session, most often a feeling. Most were scored using Likert-like scales of 4 to 6 points. They were essentially lists of feelings checked by the therapist after a session, but some were forms filled in by the supervisor or an observer that evaluated an audio recording of the session. Some characteristics of these instruments are described below. 


\section{Hostility Inhibition Scale (HIS) ${ }^{19}$}

Observers use session recordings to assess the inhibition of different hostile expressions of the therapist when interacting with the patient. The scale has five different codes that mean, for example, easily irritated or having great difficulty in allowing the emergence of anger or irritation.

\section{Feeling Word Checklist-58 (FWC-58) 22,37-39,41}

A list with 58 feelings checked by the therapist. It is divided into three, four or seven factors, according to study. In the last case, the factors are: importance, rejection, confidence, boredom, on guard, overload and inadequacy. ${ }^{37-39}$

\section{Checklist of feelings ${ }^{32,33}$}

Self-questionnaire with 48 feelings.

\section{Countertransference Questionnaire (CTQ) ${ }^{20}$}

Self-questionnaire made up of 79 items that address thoughts, feelings and behavior of the therapist in relation to the patient. The items are distributed into eight factors: overload, desperation, positivism, superinvolvement, sexuality, disinterest, protection and criticism.

\section{Gegenübertragungs-Rating (GR) ${ }^{26}$}

Self-questionnaire with 31 feelings, grouped into four factors: difficulty, friendliness, helpfulness and despair.

\section{Countertransference Assessment Scale (CTAS) ${ }^{25,40}$}

Self-questionnaire made up of 23 items distributed into three domains: closeness, distance and indifference. The feelings elicited in the beginning, middle and end of the sessions are evaluated. The list of feelings was adapted in a qualitative study. ${ }^{23}$

\section{Countertransference Factor Inventory (CFI) ${ }^{27,43}$}

An inventory of 50 items divided into 5 subscales that measure CTM attributes. It also has a revised version with 26 items. ${ }^{30}$

\section{Impact Message Inventory (IMI) ${ }^{29}$}

Self-questionnaire based on the premise that the patient's inter-personal problems may elicit some emotional responses from the therapist, called impact messages. IMI is made up of 90 items divided into eight domains: hostility/domain, hostility, hostility/ submission, submission, friendship/hostility, hostility/ submission, submission, friendship/submission, friendship and friendship/domain. It also has a circumplex version with 56 items. ${ }^{28}$

\section{Countertransference Index (CTI) ${ }^{27,34}$}

Supervisor assesses CTB using the CTI, which indicates the degree at which the therapist's behavior reflects areas of unresolved conflicts. It is made up of a single item to assess how much the therapist behavior during the session affected CT.

\section{Inventory of Countertransference Behaviors $(\text { ICB })^{34}$}

Filled out by the therapist and an external evaluator that may be the supervisor that assesses CTB, this inventory has 32 items distributed into positive and negative factors. There is also a 10 -item version called countertransference behavior measure (CBM). ${ }^{35}$

\section{Rating of Emotional Attitudes to Client by Ther- apists (REACT) ( $36,42^{2}$}

Self-questionnaire with 40 items divided into four factors: positive connection with the patient; conflict of the therapist with himself/herself; the therapist's own needs and conflicts; and conflicts of the therapist with the patient. The difference from other questionnaires is that it addresses issues that are observed out of the sessions; for example, it assesses the presence of thoughts about the patient out of the session.

\section{Circle $^{21}$}

In the study analyzed in this review, the therapist filled out the instrument, which has 16 items and a 10-point Likert-like scale. After that, an external observer listened to the audio recordings of the sessions. Points of divergence between the information provided by the therapist and by the observer were assessed.

\section{What were the settings, patients, therapists and type of therapy?}

Almost all studies clearly described their setting. Most were conducted in outpatient clinics of universities involved in therapist training, ${ }^{21,23,26,29,31,36,42}$ followed by

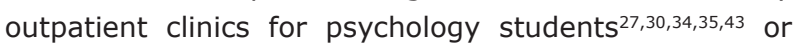
centers for the treatment of victims of violence. $24,25,40$ The other settings were children's hospitals (parents), ${ }^{19}$ private offices, ${ }^{20}$ veteran's hospital, ${ }^{21}$ hospital for victims of the Second World War, ${ }^{28}$ psychotherapy unit of a general psychiatric clinic $^{32,33}$ and day-hospital. ${ }^{37-39}$

In general, the studies did not provide detailed descriptions of therapists and did not provide information about, for example, their professional category, age or experience. However, the therapists were students, ${ }^{19,27,30,35}$ psychiatry residents $23,24,25,40$ and professionals from other areas, such as nurses and art therapists, in addition to psychologists and psychiatrists. ${ }^{28,37-39}$ 


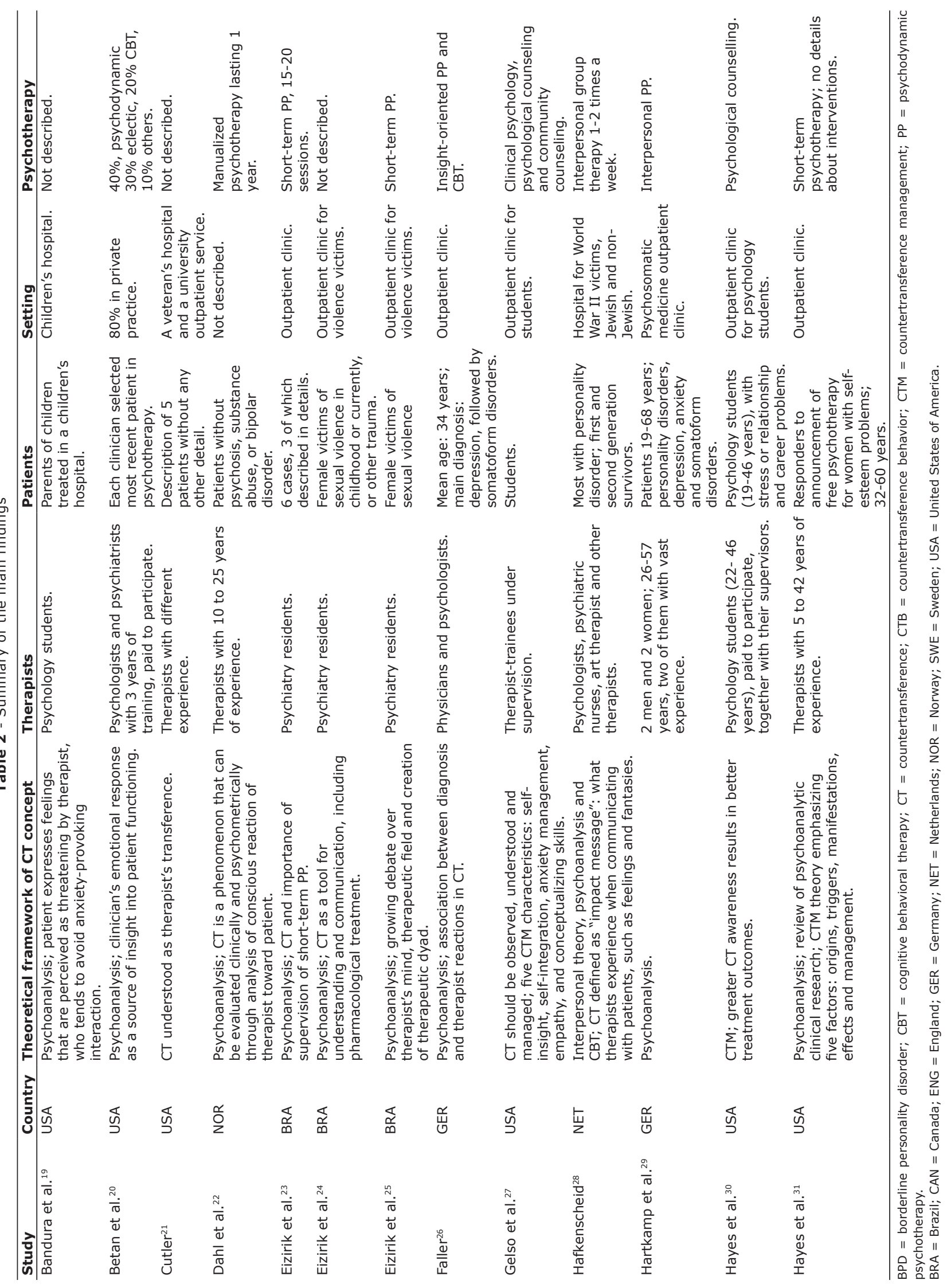




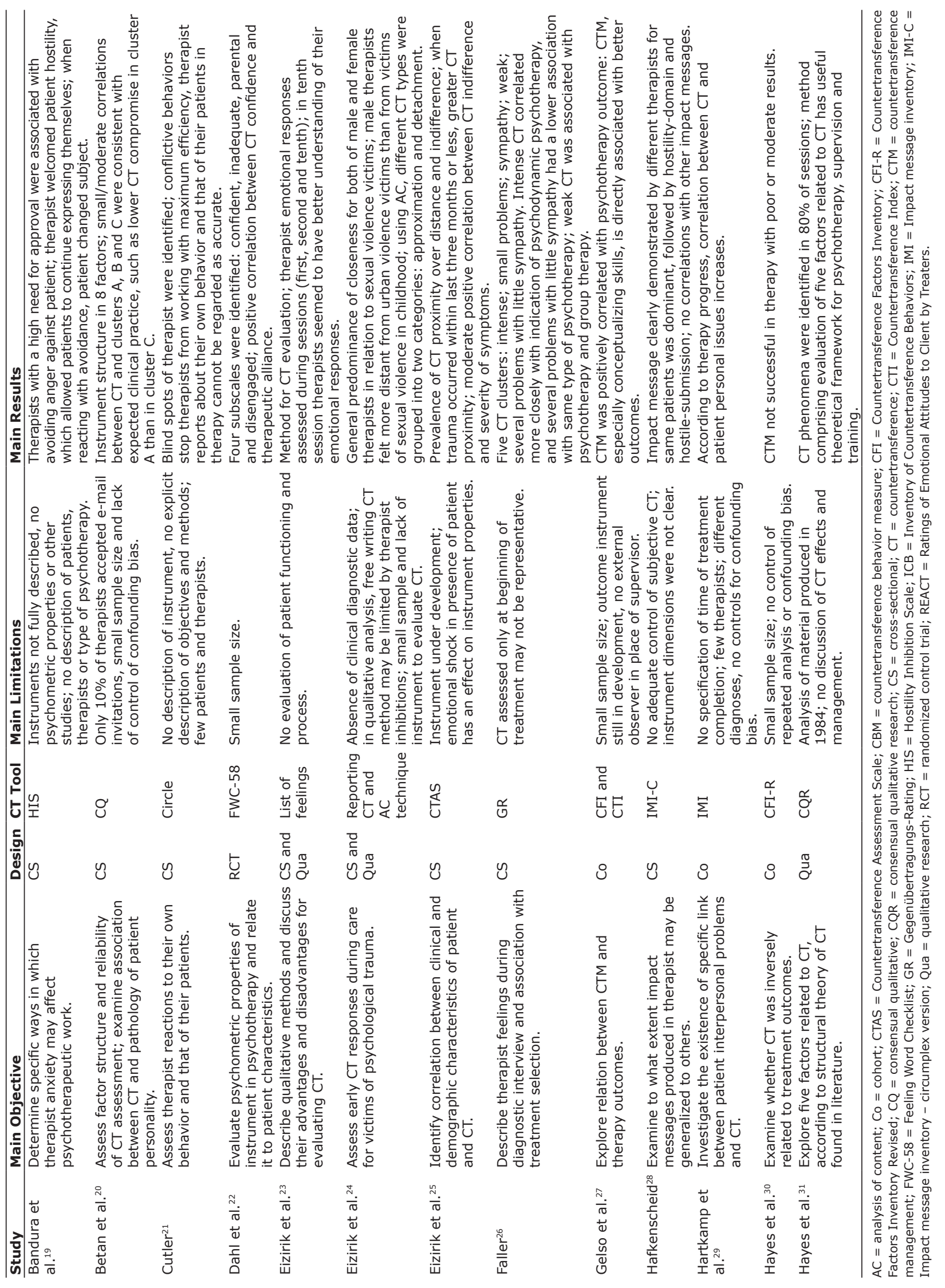




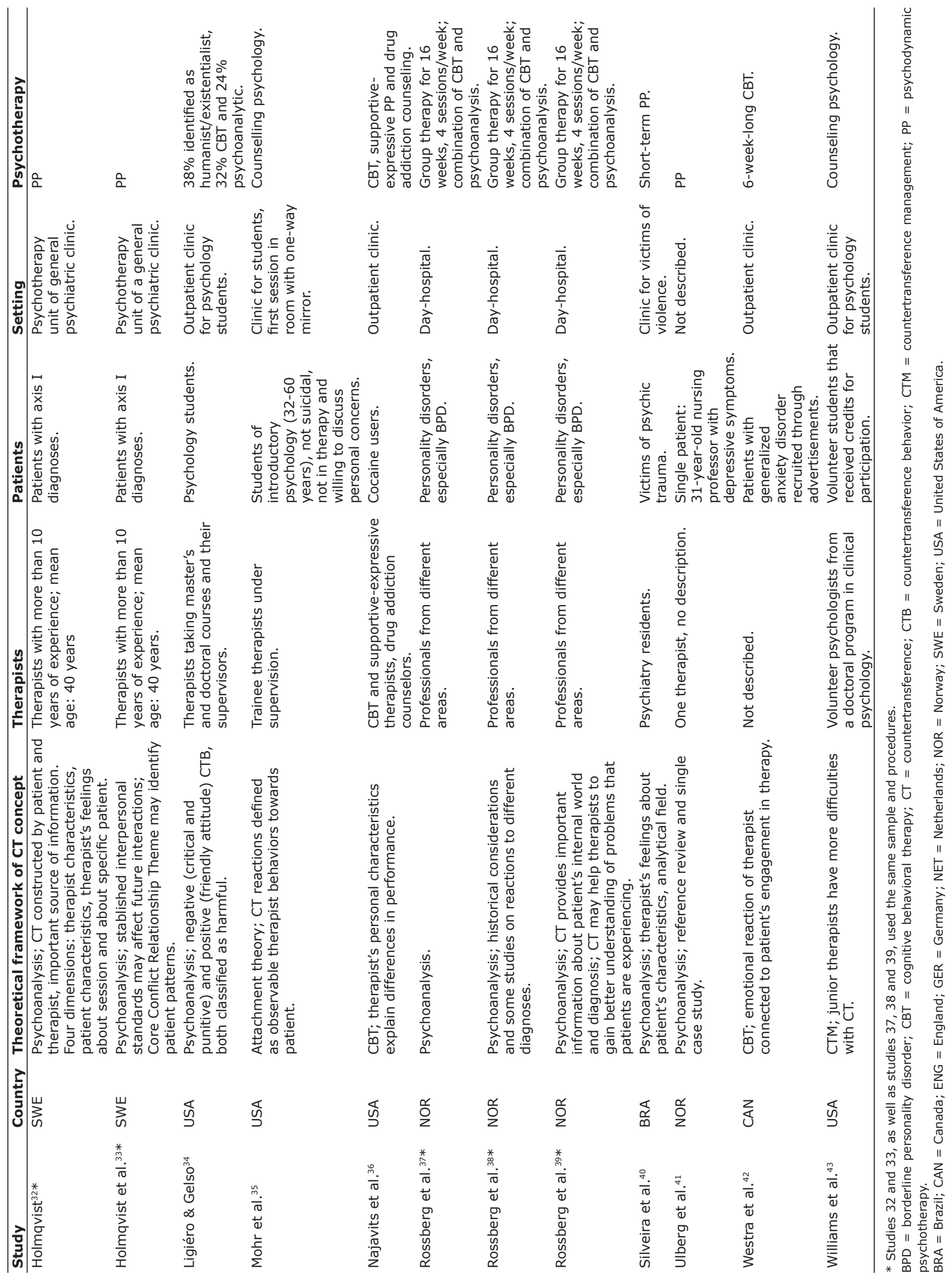




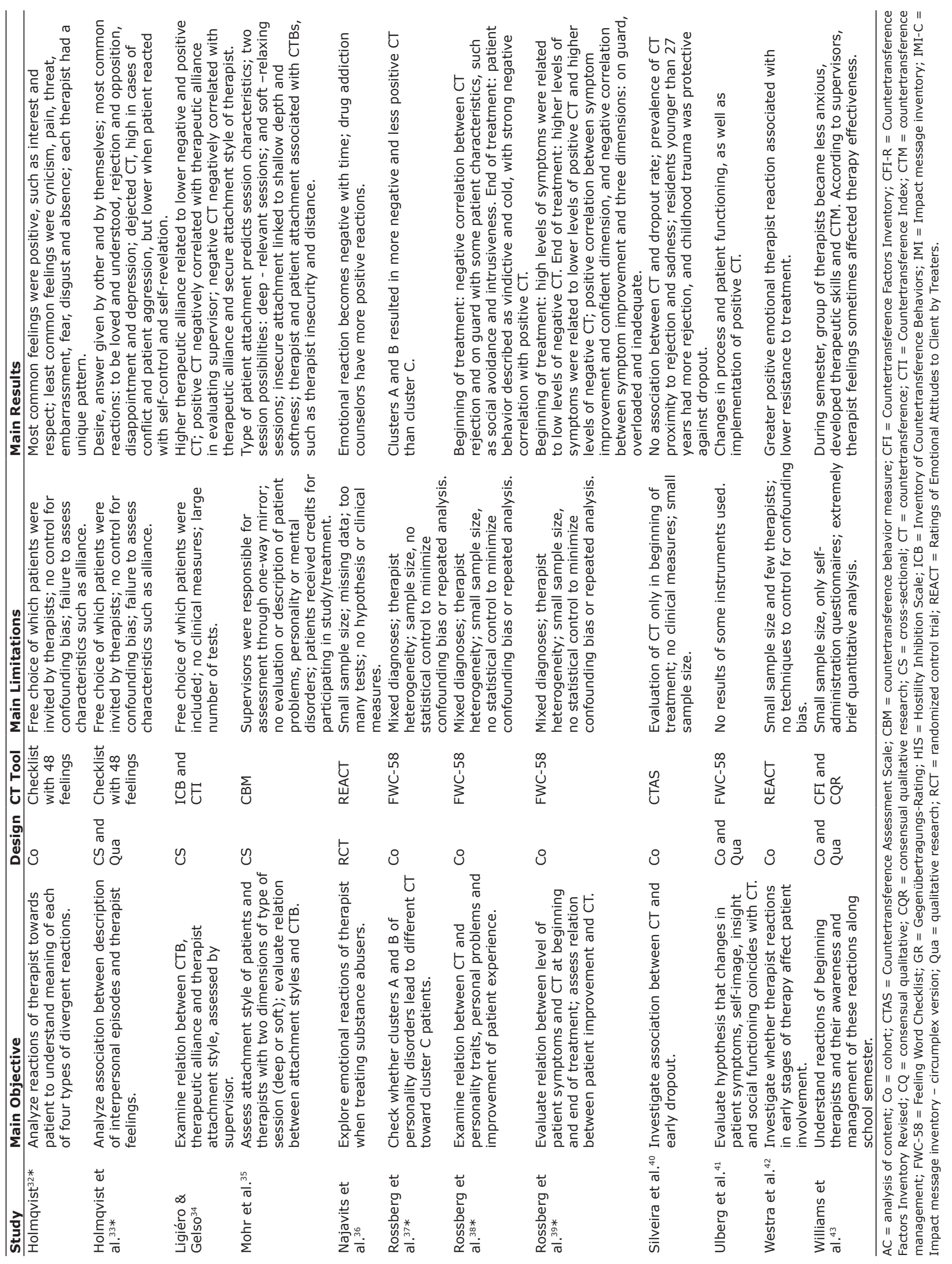


Some studies included patients with specific diagnoses or conditions, such as victims of urban and sexual violence, ${ }^{24,25,40}$ psychology students, ${ }^{27,30,34,35,43}$ and patients with depression, ${ }^{41}$ generalized anxiety, ${ }^{42}$ cocaine dependence, ${ }^{36}$ personality disorders, ${ }^{28,37-39}$ axis I diagnoses, ${ }^{32,33}$ self-esteem problems, ${ }^{31}$ and other disorders. ${ }^{26,29}$ Some studies did not describe patient characteristics.

The main psychotherapy models were long-term $\mathrm{PP}_{1} 22,32,33,41$ short-term $\mathrm{PP}^{23,25,32,40}$ and psychological counseling. $27,30,35,43$ Some studies included interpersonal group therapy, ${ }^{28}$ group therapy using CBT and $\mathrm{PP}_{1}{ }^{38,39,40}$ shortterm psychotherapy, ${ }^{31}$ and CBT.42 Other studies combined different types of psychotherapy,,$^{20,26,34,36}$ and some did not provide any description of type of therapy..$^{19,21,24}$

\section{What were the main objectives and results?}

The main objective of all studies was to evaluate the relation of different aspects of $\mathrm{CT}$ to patient diagnosis and evolution. Although studies that evaluated only psychometric properties of scales were excluded, two studies that assessed the association between CT and patient characteristics were kept. ${ }^{20,22}$

Essentially, CT was described as positive when it represented feelings of closeness, respect and wellbeing toward the patient, whereas negative feelings were unpleasant and related to distancing, such as anger and overload. Two studies found a predominance of positive feelings, such as interest, respect ${ }^{32}$ and feeling of being loved and understood. ${ }^{33}$ A study that assessed the reactions that patients elicited in different group therapists found an important relation between some CT dimensions, such as dominance, hostility and submission, and different therapists. ${ }^{28}$ The development of CT during the course of therapy was analyzed in a study using short-term PP that evaluated therapist responses in the first, second and tenth sessions and found that the therapists seemed to have a better understanding of their own reactions from the tenth session onward. ${ }^{23}$

A study that included only one patient and therapist dyad found that positive $\mathrm{CT}$ increases over the course of therapy. ${ }^{41}$ A different result was found in a study with drug addicts, in which $\mathrm{CT}$ became negative with the passing of time, except when the therapist was a drug addiction counselor. ${ }^{36}$ Another study found that the positive correlation between $\mathrm{CT}$ and interpersonal patient problems increased over time. ${ }^{29}$

Some studies about CTM found that CTM was associated with treatment results, ${ }^{27,30,31,43}$ and one found that therapists that performed adequate CTM became less anxious and, according to the assessment of their supervisors, more efficient. ${ }^{43}$
The therapeutic alliance (TA) was evaluated in three studies with controversial results. The first study, which used different diagnoses and manualized PP, found a positive correlation with positive CT. ${ }^{22}$ The second study found a negative correlation between TA and both positive and negative CT. ${ }^{34}$ The third found $a$ moderately high positive correlation between CT and TA in the therapist version, but a weak correlation in the patient version. ${ }^{36}$

Resistance and therapist attachment style were assessed. A study that included patients with generalized anxiety disorder found that a greater emotional reaction of the therapist (CT) was associated with lower resistance to treatment. ${ }^{42}$ It also found that insecure attachment of the therapist was associated with distancing СTB when treating psychology students. ${ }^{35}$

Three studies included patients with personality disorders. They found that patients with clusters A and $\mathrm{B}$ personality disorders elicited more negative and less positive CT than those with cluster $\mathrm{C}$. Moreover, in the beginning of the treatment, there was a negative correlation of feeling rejection and on guard with some patient characteristics, such as social avoidance and intrusiveness. ${ }^{37}$ In the end of the treatment, a strong negative correlation was found between vindictive and cold patient behaviors and positive CT. ${ }^{38,39}$

Three studies assessed CT elicited by sexual and urban violence victims. In the first, there was a general predominance of closeness to sexual violence victims, although male therapists felt more distant from urban violence victims than from victims of sexual violence in childhood. ${ }^{24} \mathrm{~A}$ study that assessed the initial reaction toward patients found a positive and moderate correlation between patient symptoms and indifference. When trauma occurred less than three months before, more intense closeness was found. ${ }^{25}$ The third study evaluated CT features and treatment dropout. No associations were found between outcome and specific types of CT, but rejection scores were higher in the group of therapists younger than 27 years. Moreover, childhood trauma seemed to be a protective factor against dropping out. ${ }^{40}$

Two studies evaluated therapist conflicts and CT. In a sample of parents of children hospitalized in a pediatric hospital, a high need of approval was associated with avoiding anger among therapists, which was, in turn, associated with inhibition of patient accounts. ${ }^{19}$ In patients recruited at war veteran hospitals and university clinics, conflictive therapist behaviors were associated with limitations to maximum efficiency. ${ }^{21}$

The analysis of CT and type of psychotherapy revealed that intense CT was strongly associated with PP, whereas CT responses of little sympathy were not. Group therapy was weakly associated with any type of CT. ${ }^{26}$ 


\section{Discussion}

Most studies were conducted in the field of psychoanalytic theory, which should be expected because the concept of CT was first defined by Freud and later developed by other psychoanalysts and has not been a fundamental technical element in other treatment modalities, such as CBT. However, studies using CBT made important contributions to our discussion. A study that included cocaine addicts found that personal therapist characteristics explained differences in therapist performance. ${ }^{36}$ Another study, which included patients with generalized anxiety disorder, found that the emotional tone of the therapist was associated with patient engagement. ${ }^{42}$ This review suggests that $\mathrm{CT}$ is a valuable element in CBT, as suggested by other authors.,36

One of the studies evaluated group therapy and subjective $\mathrm{CT}^{44}$ defined as emotional reactions determined by therapist characteristics and not patient characteristics. This study compared different therapists when treating the same group of patients. ${ }^{28}$

In general, the tools used to evaluate CT were very similar, as they were essentially lists of feelings and scales that rated $\mathrm{CT}$ from absent to very intense. The most frequent tool was the FWC-58, ${ }^{22,37-39,41}$ an option for future studies. Although there were some differences in study design, the way CT was evaluated was similar in most studies: feelings elicited in the therapist were scored after the end of the session. The assessment tools used in most studies measured the emotional responses elicited by the patient, but were limited in that they did not take into account the reactions and emotions that are part of the therapist's unresolved conflicts. ${ }^{44}$ In contrast, REACT ${ }^{36,42}$ assessed more complex feelings and expectations in relation to the patient, such as the therapist's needs. Different from all other tools was the measurement CTB in which an external observer evaluated therapist behavior using HIS, CTI and ICB. No study evaluated unconscious factors associated with $\mathrm{CT}$, such as fantasies or enactments.

Most studies were conducted in university outpatient clinics and included therapists in training. The types of patient and their diagnoses were heterogeneous, but studies that included psychology students and psychic trauma victims were predominant. Both short- and long-term PP were the most frequent type of therapy, followed by psychological counseling. Despite the predominance of psychoanalytical theory in the construction of the studies, none was conducted in traditional psychoanalytic settings. One possible explanation for that may be the distance that still exists between psychoanalysis and research.
Some further explanations about the results seem to be necessary. Isolated results may, in some cases, seem relevant. However, the studies reviewed had quality problems identified after they were evaluated using a reading sheet. The quality of the studies selected would be best evaluated if we had used assessment tools for observational studies, such as STROBE ${ }^{45}$ and CONSORT ${ }^{46}$ for the two randomized control trials. In any case, we found that the studies had some common problems, such as small sample sizes, no control for confounding bias and, especially, no controls for alpha error due to repeated analysis. The use of these assessment tools may improve the quality and relevance of future studies.

CT responses of closeness to the patient were generally predominant. CT quality was compared between different types of therapists. A study that included patients with drug addictions and therapists found that drug addiction counselors maintained positive feelings, such as tolerance, during the twelve-week treatment, whereas the other therapists, who worked with expressive-supportive PP or CBT, tended to develop negative feelings, such as anger, toward the patient. ${ }^{36}$ This result may confirm the importance of the work conducted by drug addiction counselors with this type of patient.

A study that included patients with different axis I diagnoses found an association between confidence CT and good TA. ${ }^{22}$ Another study, in which the patients were psychology students, found an association between low positive and negative CTB and good TA. This result may also be associated with treatment efficiency, because CTB, in the form of either positive or negative feelings, is considered detrimental to treatment. ${ }^{34}$ Therefore, CT may be a relevant source of information about TA quality.

Only two studies included patients with personality disorders. One of the results reported was the association of symptom severity and poor CT quality, ${ }^{28}$ which may further demonstrate the usefulness of the CT concept.

Some findings seem to be useful for the treatment of female victims of sexual and urban violence, as male therapists felt more distant than female therapists. ${ }^{24}$ Male therapists may be less efficient or may require some specific preparation during supervision and theoretical training, which may not be necessary for female therapists. In contrast with clinical expectations and possibly due to chance, one study found that childhood abuse is a protective factor against dropping out. ${ }^{25}$

The studies reviewed provided a description of some important factors in CT research and practice. CTM suggests that this construct, closely associated with the therapist, may be a tool to perform psychotherapeutic interventions. Some of the studies and the metaanalysis conducted focused on CTM. In contrast, CTB is 
associated with a classical view of CT. According to this modality, CT behaviors are detrimental to treatment, in agreement with Freud's $\mathbf{s}^{5,6}$ original description, in which CT should be avoided.

This review has focused only on studies that evaluated CT within psychotherapeutic settings, but some studies have also evaluated CT in general psychiatric outpatient care or psychiatric hospitalizations, for example. It remains unclear how CT functions in other treatment. Other studies that were not assessed because they escape the scope of this review may be relevant, such as those that include children and adolescents and those conducted in CT laboratories. No studies were found that evaluated aspects of psychotherapeutic practices associated with CT as projective identification, enactment or analytic field, which may be important elements to the understanding of patient and therapist interactions and should, therefore, be studied in future.

One of the limitations of this review was that it did not search databases of theses and dissertations or of psychotherapy teaching institutions. Moreover, the reference lists of studies not included were not reviewed.

The main contribution of this review was to briefly describe all studies retrieved and, therefore, to provide an overview of current knowledge about CT. Few studies evaluated CT in psychotherapy, which indicates that this is a research field to be further explored. Psychotherapy research remains a minor interest when compared with the investigation of biological treatments. Some of the studies reviewed were not very relevant, had important limitations or were predominantly exploratory, which may explain why results tended to be positive. At the same time, some of the results of different studies suggested similar directions and were compatible with what is expected in clinical practice. Therefore, as research methods continue evolving, specific and relevant questions about $\mathrm{CT}$ in psychotherapy and in overall care may be formulated in future studies.

\section{References}

1. Eizirik CL, Libermann Z, Costa F. A relação terapêutica: transferência, contratransferência e aliança terapêutica. In: Cordioli AV, editor. Psicoterapias: abordagens atuais, $3^{a}$ ediction. Porto Alegre: Artmed; 2008. p. 74-84.

2. Gabbard GO. A contemporary psychoanalytic model of countertransference. J Clin Psychol. 2001;57:983-91.

3. Prasko J, Diveky T, Grambal A, Kamaradova D, Mozny P, Sigmundova $Z$, et al. Transference and countertransference in cognitive behavioral therapy. Biomed Pap Med Fac Univ Palacky Olomouc Czech Repub. 2010;154:189-97.

4. Fauth J. Toward more (and better) countertransference research. Psychotherapy (Chic). 2006;43:16-31.

5. Freud S. As perspectivas futuras da terapêutica psicanalítica (1910). In: Edição eletrônica brasileira das obras psicológicas completas de Sigmund Freud versão 2.0. Rio de Janeiro: Imago; 2000.

6. Freud S. Novas recomendações aos médicos que exercem psicanálise (1912). In: Edição eletrônica brasileira das obras psicológicas completas de Sigmund Freud versão 2.0. Rio de Janeiro: Imago; 2000

7. Tyson RL. Countertransference evolution in theory and practice. J Am Psychoanal Assoc. 1986;34:251-74.

8. Eizirik CL, Lewkovicz S. Contratransferência. In: Eizirik CL, Aguiar RW, Schestatsky SS. Psicoterapia de orientação analítica: fundamentos teóricos e clínicos. Porto Alegre: Artmed; 2015. p. 310-23.

9. Winnicott DW. Hate in the counter-transference. Int J Psychoanal. 1949;30:69-74.

10. Heimann P. Oncounter-transference. IntJPsychoanal.1950;31:81-4.

11. Racker H. A neurose de contratransferência (1953). In: Racker H. Estudos sobre técnica psicanalítica. Porto Alegre: Artes Médicas; 1982. p. 100-19.

12. Racker H. Os significados e usos da contratransferência (1957). In: Racker $\mathrm{H}$. Estudos sobre técnica psicanalítica. Porto Alegre: Artes Médicas; 1982. p. 120-57.

13. Rosenberger EW, Hayes JA. Therapist as subject: a review of the empirical countertransference literature. J Couns Dev. 2002; $80: 264-70$.

14. Hayes JA, Gelso CJ, Hummel AM. Managing countertransference. Psychotherapy (Chic). 2011;48:88-97.

15. Zaslavsky J, Santos MP. Tendências atuais da contratransferência. In: Contratransferência: teoria e prática clínica. Porto Alegre: Artmed; 2005. p. 28-53.

16. Zimerman DE. Contratransferência. In: Zimermann DE. Manual de técnica psicanalítica: uma revisão. Porto Alegre: Artmed; 2004. p. 141-54.

17. Najavits LM. Researching therapist emotions and countertransference. Cogn Behav Pract. 2000;7:322-28.

18. Singer BA, Luborsky L. Countertransference: the status of clinical versus quantitative research. In: Gurman AS, Razin AM. Effective psychotherapy: handbook of research. New York: Pergamon Press; 1977. p. 433-541.

19. Bandura A, Lipsher DH, Miller PE. Psychotherapists approachavoidance reactions to patients' expressions of hostility. J Consult Psychol. 1960;24:1-8.

20. Betan E, Heim AK, Zittel Conklin C, Westen D. Countertransference phenomena and personality pathology in clinical practice: an empirical investigation. Am J Psychiatry. 2005;162:890-8.

21. Cutler RL. Countertransference effects in psychotherapy. J Consult Psychol. 1958;22:349-56.

22. Dahl HS, Røssberg JI, Bøgwald KP, Gabbard GO, Høglend PA. Countertransference feelings in one year of individual therapy: an evaluation of the factor structure in the Feeling Word Checklist-58. Psychother Res. 2012;22:12-25. Epub 2011 Oct 31.

23. Eizirik CL, Costa F, Kapczinski F, Piltcher R, Gauer R, Libermann Z. Observing countertransference in brief dynamic psychotherapy. Psychother Psychosom. 1991;56:174-81.

24. Eizirik M, Polanczyk G, Schestatsky S, Jaeger MA, Ceitlin LH Countertransference in the initial care of victims of sexual and urban violence: a qualitative-quantitative research. Rev Psiquiatr Rio Gd Sul. 2007;29:197-204.

25. Eizirik M, Schestatsky S, Kruel L, Ceitlin, LH. Countertransference in the initial visit of women victims of sexual violence. Rev Bras Psiquiatr. 2011;33:16-22. Epub 2010 Jul 2.

26. Faller $\mathrm{H}$. Therapists' affective reactions and treatment selection. An empirical study on countertransference feelings in the diagnostic process. Psychotherapeut. 1999;44:25-35.

27. Gelso CJ, Latts MG, Gomez MJ, Fassinger RE. Countertransference management and therapy outcome: an initial evaluation. J Clin Psychol. 2002; 58:861-7.

28. Hafkenscheid A. Objective countertransference: do patients' interpersonal impacts generalize across therapists? Clin Psychol Psychother. 2003;10:31-40.

29. Hartkamp N, Schmitz N, Schulze-Edinghausen A, Ott J, Tress W. [Specific countertransference experience and interpersonal problem description in psychodynamic psychotherapy]. Nervenarzt. 2002;73:272-7.

30. Hayes J, Riker J, Ingram K. Countertransference behavior and management in brief counseling: a field study. Psychother Res. 1997; 7:145-53.

31. Hayes JA, McCracken JE, McClanahan MK, Hill CE, Harp JS, Carozzoni P. Therapist perspectives on countertransference: qualitative data in search of a theory. J Couns Psychol. 1998;45:468-82.

32. Holmqvist, R. Patterns of consistency and deviation in therapists' countertransference feelings. J Psychother Pract Res. 2001;10:104-16.

33. Holmqvist, R., Hansjons-Gustafsson U, Gustafsson J. Patients' 
relationship episodes and therapists' feelings. Psychol Psychother. 2002; 75:393-409.

34. Ligiéro DP, Gelso CJ. Countertransference, attachment, and the working alliance: the therapist's contribution. Psychother. Psychotherapy (Chic). 2002;39:3-11.

35. Mohr JJ, Gelso CJ, Hill CE. Client and counselor trainee attachment as predictors of session evaluation and countertransference behavior in first counseling sessions. J Couns Psychol. 2005;52:298-309.

36. Najavits LM, Griffin ML, Luborsky L, Frank A, Weiss RD, Liese BS, et al. Therapists' emotional reactions to substance abusers: a new questionnaire and initial findings. Psychotherapy. 1995;32:669-77.

37. Rossberg JI, Karterud S, Pedersen G, Friis S. An empirical study of countertransference reactions toward patients with personality disorders. Compr Psychiatry. 2007;48:225-30. Epub 2007 Mar 29.

38. Rossberg JI, Karterud S, Pedersen G, Friis S. Specific personality traits evoke different countertransference reactions: an empirical study. J Nerv Ment Dis. 2008;196:702-8.

39. Rossberg JI, Karterud S, Pedersen G, Friis S. Psychiatric symptoms and countertransference feelings: an empirical investigation. Psychiatry Res. 2010;178:191-5. Epub 2010 May 7.

40. Silveira EMJ, Polanczyk GV, Hauck S, Eizirik CL, Ceitlin LH. Can countertransference at the early stage of trauma care predict patient dropout of psychiatric treatment? Rev Bras Psiquiatr. 2011;33:379-84.
41. Ulberg $R$, Høglend $P$, Marble $A$, Sørbye $\varnothing$. From submission to autonomy: approaching independent decision making. A singlecase study in a randomized, controlled study of long-term effects of dynamic psychotherapy. Am J Psychother. 2009;63:227-43.

42. Westra HA, Aviram A, Connors L, Kertes A, Ahmed M. Therapist emotional reactions and client resistance in cognitive behavioral therapy. Psychotherapy (Chic). 2012;49:163-72. Epub 2011 Jun 20.

43. Williams EN, Judge AB, Hill CE, Hoffman MA. Experiences of novice therapists in prepracticum: Trainees', clients', and supervisors' perceptions of therapists' personal reactions and management strategies. J Couns Psychol. 1997; 44:390-9.

44. Kiesler DJ. Therapist countertransference: in search of common themes and empirical referents. J Clin Psychol. 2001;57:1053-63.

45. STROBE Statement [Internet]. http://www.strobe-statement.org/.

46. CONSORT [Internet]. http://www.consort-statement.org/home/.

\section{Correspondence:}

Diogo Machado

Rua Padre Anchieta, 1988/101

96015-420 - Pelotas, RS - Brazil

E-mail:db_machado@yahoo.com 